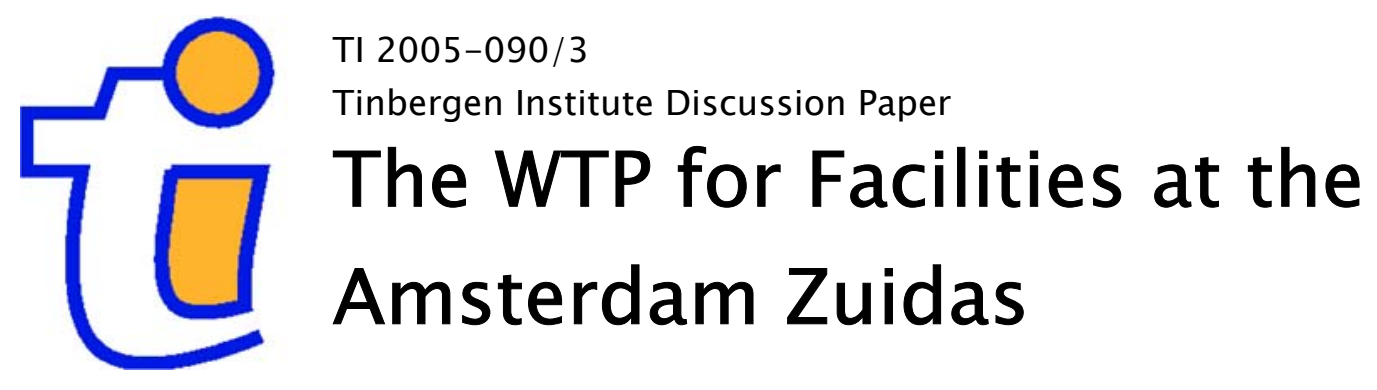

Thomas de Graaffa

Henri L.F. de Groota,b

Caroline A. Rodenburga.c

Erik T. Verhoefa,b

a Department of Spatial Economics, Faculty of Economics and Business Administration, Vrije Universiteit Amsterdam,

b Tinbergen Institute,

c Ernst \& Young, International Location Advisory Services (ILAS), Utrecht. 


\section{Tinbergen Institute}

The Tinbergen Institute is the institute for economic research of the Erasmus Universiteit Rotterdam, Universiteit van Amsterdam, and Vrije Universiteit Amsterdam.

Tinbergen Institute Amsterdam

Roetersstraat 31

1018 WB Amsterdam

The Netherlands

Tel.: $\quad+31(0) 205513500$

Fax: $\quad+31(0) 205513555$

Tinbergen Institute Rotterdam

Burg. Oudlaan 50

3062 PA Rotterdam

The Netherlands

Tel.: $\quad+31(0) 104088900$

Fax: $\quad+31(0) 104089031$

Please send questions and/or remarks of nonscientific nature to driessen@tinbergen.nl.

Most TI discussion papers can be downloaded at http://www.tinbergen.nl. 


\title{
The WTP for Facilities at the Amsterdam Zuidas*
}

\author{
Thomas de Graaff ${ }^{a \dagger}$, Henri L.F. de Groot ${ }^{a, b}$, Caroline A. Rodenburg ${ }^{a, c}$, \\ Erik. T. Verhoef ${ }^{a, b}$ \\ ${ }^{a}$ Department of Spatial Economics, Faculty of Economics and Business Adminstration \\ Vrije Universiteit, Amsterdam, The Netherlands \\ ${ }^{b}$ Tinbergen Institute Amsterdam \\ ${ }^{c}$ Ernst 83 Young, International Location Advisory Services (ILAS), Utrecht
}

September 27, 2005

\begin{abstract}
This paper reports the results of a stated preference study investigating the Willingness-topay (WTP) of employees at the Amsterdam Zuidas for the presence of non-shopping and shopping facilities. The Amsterdam Zuidas area, surrounding the current train-metro-tram station Amsterdam Zuid World-Trade-Centre, is the largest multifunctional land use project currently under development in The Netherlands. For non-shopping facilities, the results show that employees have the highest WTP for the presence of day-care centres and public transport facilities, and the lowest for public and recreation facilities. The average WTP for the presence of non-shopping facilities amounts to approximately $€ 29$ per month per employee. The WTP for the presence of shopping facilities is estimated at $€ 16$ per month per employee on average, and is in absolute value highest for supermarkets and lowest for hairdressers and dry cleaners.
\end{abstract}

Keywords: Multifunctional Land Use, Roy's Selection Model, Stated Preference Survey, WTP

JEL-classification: C42; R14.

\footnotetext{
${ }^{*}$ We would like to thank Piet Rietveld for useful comments on a previous version. We also benefited from discussions at the conference "Ruimteconferentie 2004", organised by the Dutch Spatial Planning Bureau (RPB) held in Rotterdam, The Netherlands, 2004, and at the $45^{\text {th }}$ Congress of the European Regional Science Association held in Amsterdam, the Netherlands, 2005. This research has been made possible by a BSIK Habiforum research grant. The usual disclaimer applies.

${ }^{\dagger}$ Corresponding author. Tel +31 (0)20 5986092. Email: tgraaff@feweb.vu.nl.
} 


\section{Introduction}

Railway stations can function as local centres of economic activity. Especially larger stations, at strategic nodes of the network, benefit from economies of traffic density, which means by definition that a large numbers of passengers use that station. Such economies, and the numbers of passengers, often grow substantially further when the station acts as a node both for (inter-) regional heavy rail and for (urban) light rail systems or bus networks. Stations such as Euston, Paddington or Victoria are well-known examples from the London network. Such stations are often capable of attracting a wide variety of economic activity, not only including shops of all sorts but also employers and companies from the services industry that value high publictransport accessibility. Economies of traffic density and the perceived attractiveness of the location are then generally mutually reinforcing, at least until congestion, rising land rents and other diseconomies of density become problematic.

This mutually reinforcing character implies that the establishment of such sub-centres may not always arise spontaneously, but may instead require coordinated planning of transport networks, stations areas, and real estate investments in the direct vicinity. When public governments are the key actors in such planning procedures, they will often desire a clear insight into the social costs and benefits of alternative development plans. But such costs and benefits can not always be observed directly in actual markets, especially not when these effects concern external effects such as economies of agglomeration or congestion, or when the markets concerned simply do not yet exist. It is then natural to try and evaluate such effects either by looking at actual behaviour in related markets ('revealed preferences') or by studying hypothetical behaviour in imaginary markets through questionnaire research ('stated preferences'). This paper presents a study of the second type, focussing on employees' evaluation of various services in a so called multifunctional development that is currently considered for the Amsterdam Zuidas Area, surrounding the current train-metro-tram station Amsterdam Zuid World-Trade-Centre.

Multifunctional land use projects, such as considered here, aim to concentrate and combine several socio-economic functions in one and the same area so as to save scarce land and to exploit synergies between land use functions. Because of the high intensity of land use, such areas are normally planned near public transport nodes. Not only would they create scope for the exploitation of economies of traffic density in public transport, but also would an exclusive dependence on road transport often mean that traffic congestion would seriously endanger a smooth functioning of the project.

Despite the potential benefits of multifunctional land use projects, the realisation is oftentimes difficult. Cost considerations, and the distribution of the financial burden across different stakeholders, can be important obstacles during the decision-making process. Information on 
the costs and benefits for different groups of stakeholders in multifunctional land use projects is of crucial importance to provide a better foundation for investment decisions in multifunctional land use projects (see for an introduction into the multifunctional land use inter alia, Jacobs 1961, Coupland 1997, Priemus et al. 2000). Many of the benefits stemming from multifunctional land use can not be measured directly (Nijkamp et al. 2003). Therefore, a key question is how one could determine the value that people attach to multifunctional land use patterns .

Previous research indicates that people attach positive values to multifunctional land use projects. ${ }^{1}$ One of the reasons may be that multifunctional land use has a positive impact on the way people perceive and appreciate the built-up environment (Van Wee 2003). Another possible reason is the existence of an 'option value', which expresses the value people derive from having access to goods or services, independent of whether they actually use it (Weisbrod 1964, Johansson 1987, 1991). In railway station areas, the option value might stem from possibilities people have to access different transport modes (Geurs and Ritsema van Eck 2001). There might also be a conventional 'use value' associated with the design of a multifunctional site, when some of the functions involve goods and services that the site's visitors want to consume. In this paper we will concentrate on such more tangible 'use values' for the presence of different facilities at the Amsterdam Zuidas area by a particular group of stakeholders, viz. the employees.

The Amsterdam Zuidas area is the largest multifunctional land use project currently under development in The Netherlands, and is situated in the South-Western part of Amsterdam, along the orbital motorway near the current train-metro-tram station Amsterdam Zuid WTC. In the mid 1990s, major private investors started to express interest in the Zuidas area. The goal of the city government, supported by the local business elite, became to capitalise on market interest in the area and to develop the Zuidas as an internationally-oriented office location, well accessible from Schiphol Airport (7 minutes by train) and in the future even more accessible as Zuid WTC would also become a High Speed Train (HST) station (Amsterdam 2004). Important aims are to strengthen its position as a location for 'high-quality services'. The city council expects that this will lead to the attraction of (international) companies and the generation of extra direct as well as indirect employment (DRO 1998). Over the years, the development plans for the Zuidas area have changed from a high-end office district towards a multifunctional area with mix of offices, houses and facilities (DRO 2004). In one of the current development plans, infrastructure for car, train (including high-speed train), tram and metro will be integrated on a subterranean level over a length of about one kilometre. On top of this, a mixture of houses, offices and facilities

\footnotetext{
${ }^{1}$ Typically, this research focuses on the impact of multifunctional land use on housing prices. Geoghegan et al. (1997) found that diversity and fragmentation of land use has a (marginal) positive on housing prices. More recent research shows that housing prices increase with their proximity to and with increasing amount of public parks and commercial land use (Song and Knaap 2004) or with permanently preserved open space (Irwin and Bockstael 2001, Irwin 2002) close to the residential property.
} 
will be built. A railway station (Amsterdam Zuid-WTC) is currently to be found in the centre of the Zuidas area. Due to the major expansion of the area, the railway station will develop into the fifth largest station of The Netherlands (in terms of number of travellers) and will be a main transport hub for train, high-speed train, metro and tram. Due to the high investment costs in especially infrastructure, insight in willingness to pay by stakeholders in projects such as the Zuidas is of large importance and can be used as input in indirect cost-benefit analyses.

Since the presence of particular facilities at a particular site is a non-traded good, it is not possible to directly derive its value directly from market transactions. Instead, indirect measures have to be used. One option is to use a hedonic wage analysis, in which one could compare the income of employees at the Zuidas with those of employees in areas that, ceteris paribus, do not have the same facilities that respondents at the Zuidas have. The problem with this approach, however, is that at the Zuidas the availability of the facilities to be valued is currently still relatively low, which means that it is not yet fully representative for what we consider as a multifunctional area. The valuation of multifunctional land use is therefore unlikely to show up in wage differentials.

An alternative, which will be used here, is to make use of individuals' stated behaviour, on hypothetical markets for multifunctional land use characteristics. The most straightforward economic measure to express how employees assess (the use of) a multifunctional site is their willingness to pay (WTP) for the relevant characteristic of multifunctional land use, which can identified by means of a stated preference survey (see for an overview of stated preference surveys, e.g., Louviere et al. 2000). Willingness to pay surveys allow one to infer price-related changes in behaviour, from hypothetical price changes. WTP surveys basically measure potential demand for products or services by asking consumers questions such as: "Would you purchase this product or make use of this service if it was offered at this price?". In this paper we use such a questionnaire approach to quantify the benefits of specific facilities at a multifunctionally designed area, as valued by office employees around the railway station in the multifunctional Zuidas area.

Office employees will form a substantial share of the users of the Zuidas, since, in current development plans, $45 \%$ of the area consists of office space. This implies that they form an important group to consider when designing a multifunctional area. It is important to analyse how users of a multifunctionally designed area value (the use of) such an area and, moreover, how these valuations vary between users. Strictly speaking, not the benefits of the multifunctionally designed station area as such will be measured in what follows, but the benefits of the use plus existence of facilities within a multifunctionally designed area, the so-called use-value. There are of course other elements of multifunctional land use to which employees might assign positive 
values, such as the presence of employees of other companies at the location, and status or reputation of the location, but these will not be taken into consideration in this research. A questionnaire was developed that aims to provide insight into the facilities that employees prefer to use in the direct vicinity of their work location, and the values they attach to that. Both for shopping and for non-shopping facilities, respondents only had to express detailed preferences over the subset of facilities that they found the most important to have included at the Zuidas. The motivation here was to minimise the burden of going through a long list of similar stated preference questions. For non-shopping facilities, an additional feature was that bundles of most preferred facilities were to be valued. The advantages are that fewer questions had to be answered and that the risk of overstating becomes smaller. The disadvantage is that, as we shall see, the implied structure of the data requires a special treatment in the analysis. Because of this set-up of the stated preference survey, selection effects have to be dealt with. Namely, if not properly taken into account, selection effects may cause serious biases in the estimation of WTP values for the facilities at the Zuidas.

The remainder of the paper is organised as follows. A short overview of the questionnaire as well as an overview of general characteristics of the data set will be given in Section 2. Next, Section 3 deals with the issue of how to derive WTP values for both shopping and non-shopping facilities. In Section 4, the basic survey results are presented and discussed, whereafter the econometric issues and estimations are dealt with and discussed in Section 5. The last section concludes.

\section{The Questionnaire}

\subsection{The Survey}

The questionnaire was developed in electronic format (both in Dutch and in English), which respondents could fill out on the Internet. ${ }^{2}$ An invitation to participate was sent to about 6,600 employees via an internal mailing by companies located within the Zuidas area. The questionnaire consists of three main parts:

1. The first part contains general questions, such as the number of days a week people travel to work, their commuting mode, and the average travel time between home and their work location. This information is important to relate responses to individual characteristics of respondents.

2. In the second part, people are asked to express their preferences as well as their expected

\footnotetext{
${ }^{2}$ The entire questionnaire can be found on http://www.feweb.vu.nl/.../.
} 
frequency of use for different types of facilities nearby their work location: shops, catering facilities, transport facilities and other facilities such as a museum, a day-care centre, a post office, etc. The answers to these questions were used to create scenarios for which respondents were subsequently asked to express their (indirect) willingness to pay.

3. In the final part of the questionnaire we ask about personal characteristics of respondents, such as age, gender, education level, income, family situation and zip code.

\subsection{The Respondents}

The second column in Table 1 presents the descriptive statistics of the distribution of respondents in the stated preference survey. To analyse the representativeness of the sample and to offer a characterisation of the Zuidas, we present data for the active workforce in the Netherlands from 2003 (CBS 2004) in the third column of Table 1 for comparison. ${ }^{3}$

\section{[TABLE 1 ABOUT HERE]}

A comparison of the two data sets reveals characteristics in which the average Zuidas employee differs from the average employee in the Netherlands. We see quite distinctively that the average employee at the Zuidas is highly educated compared with the average employee in the Netherlands, which is reflected in the income distribution as well. This difference is probably caused by the types of companies present at the Zuidas - being predominantly headoffices of international companies and law offices -, and, consequently, the types of workers they employ. Furthermore, the active workforce at the Zuidas is relatively young compared with the active workforce in the Netherlands, and employees at the Zuidas more often live alone or together with a partner without children. Finally, we see a very high share of employees at the Zuidas using public transport. This might be because the Zuidas may have attracted companies that attach relatively great importance to accessibility by public transport, as a result of the national government who singled the location out as one that should be easily accessible by public transport. At the same time, as especially the distance from the Amsterdam Zuid-WTC railway station shows, the Zuidas as well as the dataset has many employees working close by to a large (and expanding) railway station.

\footnotetext{
${ }^{3}$ The data for the national distribution of net personal income stems from 2000 .
} 


\section{$2.3 \quad$ Representativeness}

The database contains 1,952 respondents (the response rate was therefore $32 \%$ ). Of these respondents, 1,492 went throught the entire questionnaire, and 1,188 answered all questions. ${ }^{4}$

Selection biases might result from several sources. Because we conducted an Internet survey, a selection bias might arise when not every employee has access to the Internet. In business companies this may be the case for those employees who do not need Internet access to be able to carry out their jobs. Furthermore, the sample might not be fully representative for employees at the Zuidas, since not every company in the Zuidas area participated in the survey. This is due to $(i)$ the fact that companies were not willing to participate and (ii) at that time, there was no complete overview available of all companies that were located at the Zuidas even when compared with the rest of the Zuidas. Most participating companies are located close to Amsterdam Zuid-WTC railway station, which might lead to a distorted picture in terms of, for example, commuting mode used, assessment of accessibility of the Zuidas, and preferences for facilities. Most companies located close to Amsterdam Zuid-WTC railway station are financial institutions and lawyer's offices, whereas other kinds of employment (e.g., the public sector) are located somewhat further from Amsterdam Zuid-WTC railway station.

\section{The WTP for Facilities at the Zuidas}

\subsection{Questionnaire Design}

As explained above, the questionnaire aimed to identify how much (more) people are willing to pay for the use of (shopping and non-shopping) facilities plus the existence of these facilities close to work at a multifunctionally designed site above having access to the same facilities elsewhere. ${ }^{5}$ People may, of course, have rather different preferences on the most desired type of facility, so quite a few different types of facilities were considered in the questionnaire. To avoid excessive repetition and fatigue for the respondents, it was decided to only let them value their most desired or frequently visited facility. Consequently, as we shall see shortly, the implied selfselection process (valuations are obtained only for respondents with a relatively high valuation for that facility) might bias aggregate valuation estimates if not properly accounted for.

Next, especially for non-shopping facilities, the particular presentation of the hypothetical choice situation was, although formulated as realistically as possible, uncommon to the respon-

\footnotetext{
${ }^{4}$ The response rate is satisfactory for this type of research. For comparison, Sheehan (2001) found in a literature review for the period 1998-2000 an average response rate of $31 \%$ for studies using email-surveys.

${ }^{5} \mathrm{~A}$ distinction was made between shopping facilities and non-shopping facilities, since we expect employees to make different considerations with regard to the use of these two types of facilities (and with that, differences in WTP).
} 
dents. Among the possible biases that may result from this, the so-called part-whole bias where respondents value a different good then the researcher intends - might be particularly relevant: when valuing the presence of one facility, respondents may either 'forget' that other facilities might be valuable as well and therefore overstate their WTP for the facility under consideration; or they may implicitly assume that the presence of a certain facility is indicative for the likely co-presence of another one, which would also lead to an overestimate of the 'true' WTP. To avoid this sort of misunderstanding, people were asked to value a certain set of (most preferred) of non-shopping facilities. For our estimations, this means that it is not possible to directly identify valuations for individual facilities, so that an indirect approach has to be used (see below).

Because individuals are not used to 'pay' for the access to shops, we used a slightly different approach for the valuation of shopping facilities. Again, to avoid excessive repetition, we first asked respondents for their two most frequently visited shops and, thereafter, we asked respondents about their changes in expenditure shares in both shops for four different hypothetical price levels when those two types of shops would also be present at the Amsterdam Zuidas. ${ }^{6}$

\subsection{WTP for Non-shopping Facilities}

The WTP for non-shopping facilities was obtained as follows. First, for a number of nonshopping facilities the respondents were asked to indicate how important (on a scale from 1 to 5) they personally judged the presence of that facility at the Zuidas. Next, a bundle of three non-shopping facilities was formed, including the three facilities that are most important to the respondent (say A, B, and C). The respondents were then asked for a value for the bundle of facilities containing $\mathrm{A}, \mathrm{B}$, and $\mathrm{C}$. To obtain insight into the WTP for this bundle, first a two-stage dichotomous choice question was asked. In this question we ask respondents twice to answer 'yes' or 'no' to the question of whether they are willing to pay a certain amount of money for having access to the particular combination of facilities shown. The amount of money presented to the respondents in the second question differs from the first question, and depended on the answer to the first question. The second dichotomous choice question was followed by an open-ended contingent valuation question. The exact question respondents had to answer was the following:

Suppose that you would have to buy a 'Zuidas area employee card' in order to be allowed to use the following facilities in the Zuidas area: A, B, and C. With this card, the actual use of the facilities in the Zuidas area would have the same price as

\footnotetext{
${ }^{6}$ The reason we asked for most frequently visited shops and not most preferred shops, is that in the former case we were certain that respondents because of shopping experience would have a more or less accurate idea about the 'normal' price level in these shops elsewhere.
} 
facilities that you would use outside the Zuidas area. Would you be willing to pay $€ 25$ per month for such a card?

If the respondents accepted the payment in the first question, they were asked whether they would also pay $€ 50$. If not, they were asked whether they would be willing to pay $€ 10$. Finally, they were asked to express an exact maximum amount of money they are willing to pay for the use of the bundle of facilities in an open question.

The formulation is explicitly and intentionally targeted at measuring the extra WTP for the use of facilities at the Zuidas and in principle is not influenced by characteristics such as prices for the use of facilities, etc. The specific approach raises two methodological issues. First, it is not the WTP for specific facilities that is being asked, but that for a combination of facilities instead. This means that estimating the WTP for individual facilities cannot simply be done by aggregating over respondents. Second, this approach raises a selectivity issue. Because a WTP is given for a bundle of the three most preferred facilities, mean WTP's for the total sample are probably much lower, then for the subgroups selecting a certain facility. Whereas the former issue is addressed in Section 4, Appendix A discusses the latter issue in greater detail.

\subsection{WTP for Shopping Facilities}

The questionnaire also looked at WTP values for shopping facilities. Here, we decided to make use of hypothetical 'variations' in price levels for shopping facilities to obtain an indication for the WTP of employees for making use of shopping facilities in the Zuidas. We therefore asked

the respondents to indicate their expediture shares in certain types of shops hypothetically present at the Zuidas area, for different (relative) price levels. The "expenditure share" is for this purpose defined as the share of the total expenditure in a certain type of shop as spent on the Zuidas if that type of shop were present there. The reason we asked respondents to indicate changes in expenditure share, and not changes in quantities bought of a specific product, is that questions in terms of expenses are more natural to formulate and easier to answer. Thus, we do not need to describe an unrealistic situation in which employees are asked to imagine paying an entrance fee to make use of shopping facilities, as they had to in the question about the "Zuidas employee card" used in the previous section. This is important, since people are expected to be particularly reluctant towards paying a kind of entrance fee to be allowed to make use of shopping facilities. The use of budget shares enables us to assess the responsiveness of people towards price changes in shopping facilities in a multifunctionally designed area, compared to shopping facilities elsewhere.

The type of shop for which respondents had to fill in their expenses depended on the frequency with which they had indicated in earlier survey questions to expect to make use of 
different types of shops in the Zuidas area. Shops to which respondents assigned the highest frequencies showed up in this question. In the open-ended CVM question that followed about respondents' expenditure shares in specific shops, four scenarios were presented. In the first scenario we hypothesised an equal price level at the Zuidas $\left(p_{Z A}^{0}\right)$ compared to alternative options (e.g., shops respondents currently use). In the subsequent scenarios, the (relative) price level in the Zuidas area $\left(p_{Z A}\right)$ was presented as being $10 \%, 25 \%$ and $50 \%$ higher, respectively. For each scenario, respondents had to indicate which percentage of their total expenses $(E)$ on a specific type of shop (e.g., supermarket, dependent on earlier answers) they expect to spend in their current outlet, and which percentage in an outlet in the Zuidas area.

By asking respondents to indicate their budget share in a specific shop at different price levels, we obtain indirect information about the 'excess WTP' of employees for the use of shopping facilities in the Zuidas, over using their current outlet. The extent to which demand decreases when relative prices exceed unity can namely be seen as a measure for respondents' WTP for the use of shopping facilities in the area. The responses to this question allow us to derive a demand function for purchases at the Zuidas, instead of buying these goods elsewhere. Figure 1 shows this demand function, for which the non-Zuidas price and quantity (and hence expenditures) are normalised to one.

\section{[FIGURE 1 ABOUT HERE]}

Quantities $q_{Z A}$ at different relative price levels $p_{Z A}$ can be determined by dividing total expense $E$ by the relative price level $q_{Z A}=E / p_{Z A}$ (note that $E$ is a percentage). The shaded area then gives the employees' WTP for having the shops available at the Zuidas, rather then not having them there. Respondents indicated their expenditure shares if prices at the Zuidas are 10\%, $25 \%$ and $50 \%$ higher than elsewhere, respectively. Point A shows the expenditure share at the Zuidas if prices at the Zuidas are equal to elsewhere (denoted in Figure 1 as $p_{E}$ ).

Note that sample selection again may be an issue here, since respondents were asked to respond to the open CVM question for the two most frequently visited types of shops. However, because we know the importance employees attach to the various shops as well, we are able to correct for sample selection bias, under the assumption that frequency coincides with the preference structure of employees for shopping facilities. Again, we refer to Appendix A for details. 


\section{Survey Results}

\subsection{Non-shopping Facilities}

The average maximum WTP of employees for the most-preferred combination of three nonshopping facilities at the Zuidas is $€ 6.88$ per month. Because this amount applies to the most preferred combination, this means that on average each employee is willing to spend at least $€ 6.88$ per month for having access to non-shopping facilities at the Amsterdam Zuidas. Figure 2 shows the frequencies of WTP values chosen by respondents. There is a large variation in WTP's. The WTP of $84 \%$ of the respondents is $€ 10$ or lower and only about $5 \%$ of the respondents is willing to pay $€ 25$ or more per month. More importantly, up to $49 \%$ of all values are zeros, meaning that the dataset is strongly censored.

\section{[FIGURE 2 ABOUT HERE]}

There are good reasons to expect an individual's WTP to depend on the set of facilities that is being valued. Figure 3 shows for the indicated facilities the average WTP, and the $90 \%$ confidence interval, for the bundles of three most-preferred facilities in which the indicated facility is included. The straight line shows the average WTP of all respondents (€6.88), irrespective of the bundle of facilities concerned. The right axis normalises the WTP's with respect to the grand average. A pooled-variance t-test was conducted to see if the differences between the average WTP's shown in Figure 3 are statistically significant. ${ }^{7}$

The confidence intervals have been constructed using the estimated sample variance. ${ }^{8}$ They illustrate that the differences in WTP are statistically significant for several bundles in which a specific non-shopping facility is included (their confidence intervals do not overlap). The average WTP for, e.g., those bundles in which a lunchroom is included (€6.83) differs statistically significantly from the average WTP for bundles in which a day-care centre is included. We see furthermore that employees are willing to pay relatively high amounts for the use of a bundle of three facilities in which: $(i)$ a day-care centre is included (€13.1), (ii) sport facilities are included (€10.8), or (iii) a museum is included (€10.2). The WTP for so-called public facilities is generally much lower. Perhaps people perceive access to facilities such as urban green, a railway station, etc., as a right, for which they are not willing to pay (for its use nor its presence). But the differences can of course also express different valuations of the personal use values.

\footnotetext{
${ }^{7}$ In this t-test, the 'pooled variance' reflects the assumption that the population variances of both samples are equal.

${ }^{8}$ Theoretically, minor differences compared to the t-test results could occur. These differences were, however, so small that they did not influence the conclusions.
} 
[FIGURE 3 ABOUT HERE]

To estimate the WTP for individual facilities, straightforward regression of the WTP for the bundle on the various facilities in this case would not be appropriate, primarily, as Figure 2 clearly shows, because the estimations have to be corrected for censoring (besides correcting for selectivity as explained above). The next section will deal specifically with estimation issues.

\subsection{Shopping Facilities}

As explained above, the size of the shaded area in Figure 1 represents the willingness to pay for the use of shopping facilities at the Zuidas rather than elsewhere. Because we have normalised prices and quantities and we only have information on expenditure shares, the data do not directly allow for a calculation of the WTP for the presence of specific type of shop at the Zuidas. Doing this requires an estimate of the average expenses of Dutch people in those types of shops. CBS (2004) provides data of the year 2000 for household expenses for different categories. Assuming that the average expenditure pattern of individuals in The Netherlands can be applied to employees at the Zuidas, we can calculate the WTP of employees to make use of shopping facilities at the Zuidas.

Since we asked respondents for their change in expenditure share at different price levels, we have four (estimated) data points available for each respondent. For each data point we are able to calculate the corresponding quantities by means of: $E / p_{Z A}=q_{Z A}$. The four individual observations for expenditure shares at different price levels thus enable us to find four different quantities $q_{Z A}^{\pi}$ for four price levels $p_{Z A}^{\pi}$. Thereafter, by means of ordinary least squares regression, we fitted an average quadratic demand function $p\left(q_{Z A}^{\pi}\right)=a+b q_{Z A}^{\pi}+c\left(q_{Z A}^{\pi}\right)^{2}$, in which $a, b$, and $c$ represent coefficients to be estimated. Using these estimates we are able to calculate the size of the shaded area for the average respondent, and thus the willingness to pay for a specific shopping facility.

\section{$5 \quad$ Empirical Specification and Results}

Because the observed WTPs are the respondents' most preferred WTPs we have to correct for selection effects in order to consistently estimate the mean WTP's for the whole sample. Moreover, because the survey questions were different for non-shopping and shopping facilities we will deal with both types of facilities differently, although their underlying modelling framework is identical. For further details of this underlying structure, we refer once again to Appendix A. 


\subsection{The WTP for Non-shopping Facilities}

As explained above, respondents first had to indicate their three most preferred facilities (from most to least preferred), after which they had to value this bundle of facilities. We indicate these three most preferred facilities as $j, k$ and $l$. The expected value $E\left[y_{j, k, l}\right]$ of the bundle may then be denoted as:

$$
E\left[y_{j, k, l} \mid \xi_{j}, \xi_{k}, \xi_{l}\right]=E\left[y_{j} \mid \xi_{j}\right]+E\left[y_{k} \mid \xi_{k}\right]+E\left[y_{l} \mid \xi_{l}\right]
$$

where $\xi_{z}(z \in\{j, k, l\})$ denotes the denotes the rank individual $i$ attributes to facility $z$. Assuming that $(i)$ each valuation of facility $j$ follows a $N\left(\mu_{j}, \sigma_{j}^{2}\right)$ distribution and that $(i i)$ the level of total WTP for the three most preferred facilities $j, k$ and $l\left(y_{j, k, l}^{*}\right)$ depends additively on a set of individual characteristics $\mathbf{Z}$, leaves us with:

$$
y_{j, k, l}^{*} \mid \xi_{j}, \xi_{k}, \xi_{l}=E\left[y_{j} \mid \xi_{j}\right]+E\left[y_{k} \mid \xi_{k}\right]+E\left[y_{l} \mid \xi_{l}\right]+\mathbf{Z} \beta+\epsilon_{j, k, l}
$$

with $\epsilon_{j, k, l} \sim N\left(0, \sigma_{j, k, l}^{2}\right)$ and

$$
\sigma_{j, k, l}^{2}=\sigma_{j}^{2}+\sigma_{k}^{2}+\sigma_{l}^{2}+2 * \sigma_{j k}+2 * \sigma_{j l}+2 * \sigma_{k l},
$$

where $\sigma_{z z^{\prime}}$ denotes the covariance between the value attached to facility $z$ and facility $z^{\prime}\left(z^{\prime} \in\right.$ $\left.\{j, k, l\} \wedge z^{\prime} \neq z\right)$. Using equation (1) and the appropriate specification for $\left[y_{j} \mid \xi_{j}\right]$ as explained in Appendix A yields the empirical specification. As already noted above, $49 \%$ of all observations are zeros, implying that our sample is heavily censored. Thus, we have to apply the following standard Tobit specification to equation (1).

$$
y_{j, k, l} \mid \xi_{j}, \xi_{k}, \xi_{l}=\left\{\begin{array}{cl}
y_{j, k, l}^{*} \mid \xi_{j}, \xi_{k}, \xi_{l} & \text { if } \quad \begin{array}{l}
y_{j, k, l}^{*} \mid \xi_{j}, \xi_{k}, \xi_{l} \geq 0 \\
0
\end{array} \quad \text { otherwise }
\end{array}\right.
$$

where $y^{*}$ denotes the latent variable. Because we have 17 non-shopping facilities, this would mean that we have to estimate 170 (17 means, 17 variances and 136 covariances) variables, and that is yet without including individual characteristics in the model. Because of this computational complexity, we merge the non-shopping facilities into six new more or less homogeneous groups of facilities, which leaves us with only 27 (6 means, 6 variances and 15 covariances) variables to be estimated. The new groups of non-shopping facilities encompass:

public transport : bus station, railway station, metro station, bicycle stand;

restaurants : pub, lunchroom, restaurant, snackbar; 
luxury transport : high-speed-train station, taxi stand;

day-care centre : day-care centre;

sports : sport centre;

public/recreation : library, museum, video shop, post office, park/green.

Table 2 offers the estimation results of specification 2, which are to be interpreted as shifts in the expected value ${ }^{9}$ of the latent distribution for the bundle of shopping facilities.

\section{[TABLE 2 ABOUT HERE]}

Because of the structure of the model, the coefficients reflect the marginal effects on the latent distribution and can therefore only be interpreted relatively. Thus, age does not seem to have a large impact on the WTP for non-shopping facilities. Employees who work four or five days a week at the Zuidas, however, would like to spend more for non-shopping facilities compared to workers who travel less to the Zuidas. This result is not surprising, since these workers are expected to use these facilities most often, as they spend most time at the Amsterdam Zuidas. The income measures do not show to be significant, nor do they show any clear pattern. Travel time characteristics display an intriguing behaviour. It seems that WTP conditional on travel time follows an inverse U-shape pattern, indicating that workers living very close by or far from the Zuidas have lower WTP values for non-shopping facilities. Employees living close by may also use their own facilities at home while employees living far from the Zuidas may leave early because of higher commuting time and may therefore use non-shopping facilities relatively less. Perhaps related, employees commuting with bus, train or tram seem to be willing to spend most on non-shopping facilities compared to workers who come by car of bike. Females have on average also a higher WTP and finally, employees coming from less dense urbanised regions are also willing to spend more. The latter is probably due to the fact that there are less nonshopping facilities in sparsely populated areas, so that every increase in the availability of these facilities would be appreciated.

The distribution parameters of the WTP for each non-shopping facility are even more difficult to interpret directly, because relative changes between the WTP for facilities do not only depend upon the expectations but also upon the standard errors. To clarify this point, Figure 4 offers the (latent) distribution of the WTP for each non-shopping facility.

\footnotetext{
${ }^{9}$ Note that the expected value of the latent distribution $\left(y_{j, k, l}^{*}\right)$ is simply $E\left[y_{j} \mid \xi_{j}\right]+E\left[y_{k} \mid \xi_{k}\right]+E\left[y_{l} \mid \xi_{l}\right]+\mathbf{Z} \beta$.
} 
[FIGURE 4 ABOUT HERE]

Figure 4 and Table 2 clearly shows that day-care centres have the highest WTP expectation and restaurants the lowest. However, because we are only interested in the observed WTPvalues, we should restrict our attention to the areas below the distributions to the right of the y-axis. This means, e.g., that, although expected latent WTPs for public/recreation facilities are higher than for sport centres, expected observed WTPs are lower. This is because the latent expected means of the distribution are negative, due to the large number of zero observations. Moreover, the parameters of these distributions are only valid for the base case - in this case we are looking at a sample of young car driving males, who work less than four days per week at the Zuidas, who are low-earners and live in very sparsely populated municipalities.

Because we are interested in the expected observed WTP-values for the full sample as well, we transform the latent WTP expectation into the observed WTP for each employee and for each facility (conform, e.g., Maddala 1983). ${ }^{10}$ These WTP expectations are given in Table 3.

\section{[TABLE 3 ABOUT HERE]}

The results in Table 3 clearly show that day-care centres, public transport facilities and restaurants are valued most highly among the non-shopping facilities (to be) present at the Amsterdam Zuidas. Public and recreation facilities are valued least highly by employees. Note that the sum of all WTP-values is the sum again of all 17 non-shopping facilities and not of the six groups. Thus, e.g., public transport was composed of four facilities and its WTP should therefore be multiplied by four to calculate total WTP for all non-shopping facilities.

\subsection{The WTP for Shopping Facilities}

In the questionnaire six shop types were distinguished: namely, supermarkets, drugstores, hairdressers, dry cleaners, flower shops and book shops. Each individual was first asked to indicate her two most frequently visited shops and subsequently indicate her change in expenditure level for both shops when prices were $0 \%, 10 \%, 25 \%$, and $50 \%$ higher. Although the two variables 'most frequently visited shop' and 'most preferred shop' are not identical, the same type of selfselection bias as before is very likely to occur. Each respondent had to indicate her preference ranking of shops as well, so that for each individual we are able to construct a ranking structure $\xi_{s}$ for each facility $s$ (see again Appendix A). Normalising the prices $\left(p_{Z A}^{0}\right)$ at one, enables us

\footnotetext{
${ }^{10}$ Basically, this means that all negative latent observations are set at zero.
} 
to specify the relation between quantities $\left(q_{Z A}^{\pi}\right)$ and prices levels $\left(p_{Z A}^{\pi}\right)$ for shopping facility $s$ as follows:

$$
q_{Z A}^{\pi}\left|\xi_{s}=\mathbf{D} \gamma\right| \xi_{s}+\mathbf{Z} \beta \mid \xi_{s}+\epsilon_{s}
$$

where $\mathbf{D}$ is a matrix of dummies for price levels at the Zuidas $\left(p_{Z A}^{\pi}\right)$ with 24 columns - four relative price levels $\pi(\pi \in\{1.0,1.1,1.25,1.5\})$ for each of the six shopping facilities - , and $\mathbf{Z}$ is the same set of individual characteristics as used for the non-shopping facilities. Table 4 offers the estimation results of specification (3).

\section{[TABLE 4 ABOUT HERE]}

Table 4 focusses especially on the impact of individual characteristics on the WTP for shopping facilities at the Amsterdam Zuidas. Although the individual characteristics directly influence expenditure shares in shopping facilities at the Zuidas - and the corresponding quanties -, direct inference on the level of WTP values is not feasible because information on individual variation in monthly household expenditures is not available. However, we are able to interpret the sign of the coefficients as the direction WTP values change due to individual characteristics.

Almost all coefficients are statistically significant. First, young employees seem to have a higher preference for shopping facilities than older employees, which may indicate that they are less tied to local shops around the place of residence. As could be expected, workers who work more at the Zuidas are also willing to pay more for the presence of shops, as the likelihood also increases that they actually will make use of these facilities. The income parameters are less significant than the others, but point to the - theoretically justifiable - pattern that workers with a higher income have a higher WTP as well. Opposite to the estimates for non-shopping facilities, those workers with lowest travel time also have the highest WTP for shopping facilities. Probably, these workers expect not only to make use of these shops during working hours, but also during non-working hours, e.g. the weekends, as well as these shops would be rather close to their place of residence. Workers who walk or cycle to work have the lowest WTP for shopping facilities and workers who use the car and especially bus or tram have the highest WTP. Most likely, this is correlated with the ease of carrying the purchases made at the shops home. Just as for non-shopping facilities, women seem to have a higher WTP for shopping facilities as well. And finally, both workers who live in very densely and workers who live in very sparsely populated areas have a high preference for shops at the Zuidas. This is probably due to two effects. First, workers who live in rather rural areas value better access to shops anyway, irrespective whether they are present at the place of residence or at the place of work. 
On the other hand, workers who live in very densely populated areas probably live in residential areas with few shopping facilities and hence value better access to shopping facilities as well.

Note that the price dummies in Table 4 directly give the effect of prices on quantities for a sample of young car driving males, who work less than four days per week at the Zuidas, who are low-earners and live in very sparsely populated municipalities. However, we make a few general comments before looking at the total sample. For all shop types, the analyses result in vertical intercepts within the range 0.56 to 0.36 , implying that the employee belonging to the sample as decribed above is prepared to spend $36 \%$ to $56 \%$ of his total expenditure on shops at the Zuidas when prices will remain the same. For hairdressers and dry cleaners, workers will be actually spending less at the Zuidas compared to their normal expenditure pattern when prices will be raised to high at the Zuidas.

We use the approach as explained in subsection 4.2 to calculate sample average WTP values for all shopping facilities. We use the estimates provided by CBS (2004) for the average monthly household expenditures at supermarkets $(€ 260)$, drugstores (€35), hairdressers (€13), dry cleaners (€1.40), flower shops (€11.40), and at bookshops (€26.70). Now, the second column in Table 5 shows the share of an employees' average monthly expenses in a specific type of shop he or she is willing to spend extra for the use of that type of shop in the Zuidas area. The third column shows the conversion into corresponding WTP-values.

\section{[TABLE 5 ABOUT HERE]}

Table 5 shows that the WTP values for almost all shops are much lower than for supermarkets, which is primarily due to the fact that average monthly household expenses for non-supermarket shops are much lower than for supermarkets. If we, however, look at the WTP for the use of different types of shops in a multifunctionally designed area as a share of average monthly expenditures, we see that the relative WTP is more or less equal for all kind of shops, except for hairdressers. Presumably, workers have a high preference to have their hair cut close to home.

\section{Conclusion}

Larger railway stations often attract, and benefit from, various types of economic activity. This makes the planning of stations and areas around them a complicated task, for which it is important to have a clear idea of the benefits and costs associated with different types of designs. This paper studied this question empirically in the context of a multi-functional design of the area around the Amsterdam Zuid WTC rail-tram-metro station, focussing on the valuation by 
local employees of various hypothetical shopping and non-shopping facilities. To that end, a stated preference survey was held, in which employees at the Amsterdam Zuidas were asked to indicate their WTP for their most preferred facilities - ranging from public transport facilities and restaurants to various types of shops. To find the true WTP for each individual facility, we had to control for censoring and selection effects.

Regarding non-shopping facilities, employees appear not to be willing to spend much on public and recreation facilities. Probably, workers expect these facilities - post offices, greenery, libaries, etc. - to be present anyway, and are not used to think in terms of paying for them (while they do of course via local taxes). Moreover, workers seems to have a higher preference for public transport facilities than for more luxury type of transport facilities. Obviously, the first type is used more often by a large share of the employees at the Zuidas. Only a small percentage of the employees at the Zuidas will make use of taxi's and high speed train on a regular basis.

As for shopping facilities, employees at the Zuidas have a high absolute WTP for supermarkets, but only because they spend a large part of their budget to supermarkets anyway. Looking at WTP relative to current expenditures reveals that for the availability of most shopping facilities at the Zuidas, employees are willing to pay $3 \%$ to $5 \%$ of current expenditures. Only for hairdressers, their change in expenditure level seems to lag behind with only $1.5 \%$.

The analysis of the average WTP of employees for the total bundle of non-shopping and shopping facilities reveals a value of $€ 45.18$ per month for the average employee, or $€ 542.16$ per year, for the full set of facilities considered. Moreover, the analysis reveals that most WTPs for facilities are positively correlated with each other. This indicates that there are unobserved factors present that - although partly corrected for - influence the WTP employees have for facilities at the Zuidas. These unobserved factors may be related to personal live - e.g. life-style and personality - or work related - e.g. ambition and type of workplace.

Ideosyncratic factors that we are able to directly control for, show that the WTP for facilities at the Zuidas depends significantly on individual characteristics. Moreover, it appears that the type of facility (shopping versus non-shopping) seems to appeal to different groups of employees. For example, employees below 30 have a high preference for shopping facilities, while employees between 30 and 40 seem to prefer non-shopping facilities more. The latter may be related to child care. However, the largest different can be found in travel time, where workers living close to their works have a high preference for shopping facilities and workers living farther away have a high preference for non-shopping facilities. This indicates a significant difference in behaviour between these two types of employees. If present, workers who live further away are willing to spend time and money to non-shopping facilities at the place of work, while workers who live 
close to work seem to be more indifferent to the presence of these types of facilities. However, the latter group is willing to spend more at shopping facilities close to work. This last point underlines that functions present at a multifunctional land use may often be strongly related to each other. Consequentially, the presence of other functions may be a critical success factor.

\section{References}

Amsterdam, G.: 2004, Economische Visie Zuidas Amsterdam, Projectbureau Zuidas, Amsterdam.

CBS: 2004, Statistische Berichten, Centraal Bureau voor de Statistiek, Voorburg/Heerlen.

Coupland, A.: 1997, An Introduction to Mixed Use Development, Spon, London.

DRO: 1998, Masterplan Zuidas, Projectbureau Zuidas, Dienst Ruimtelijke Ordening, Amsterdam.

DRO: 2004, Visie Zuidas: Stand van Zaken 2004, Projectbureau Zuidas, Dienst Ruimtelijke Ordening, Amsterdam.

Geoghegan, J., Wainger, L. A. and Bockstael, N. E.: 1997, Spatial landscape indices in a hedonic framework: An ecological economics analysis using gis, Ecological Economics 23, 251-264.

Geurs, K. T. and Ritsema van Eck, J. R.: 2001, Accessibility measure: Review and applications. evaluation of accessibility impacts on land-use transport scenarios, and related social and economic impacts. Bilthoven: National Institute for Public Health and the Environment. RIVM Report 408505006.

Greene, W. H.: 1993, Econometric Analysis, Macmillan Publishing Company, New York.

Heckman, J. J. and Honoré, B. E.: 1990, The empirical content of the roy model, Econometrica 58, 1121-1149.

Irwin, E. G.: 2002, The effects of open space on residential property values, Land Economics 78, 465-480.

Irwin, E. G. and Bockstael, N. E.: 2001, The problem of identifying land use spillovers: Measuring the effects of open space on residential property values, American Journal of Agricultural Economics 83, 698-704.

Jacobs, J.: 1961, The Life and Death of Great American Cities, Penguin, Harmondsworth. 
Johansson, P. O.: 1987, The Economic Theory and Measurement of Environmental Benefits, Cambridge University Press, Cambridge.

Johansson, P. O.: 1991, Valuing Environmental Damage. Economic Policy Towards the Environment, Blackwell Publishers, Oxford.

Louviere, J. J., Hensher, D. A. and Swait, J. D.: 2000, Stated Choice Methods: Analysis and Applications, Cambridge University Press, Cambridge.

Maddala, G. S.: 1983, Limited Dependent Variables and Qualitatitve Variables in Econometrics, University Press, Cambrigde.

Nijkamp, P., Rodenburg, C. A. and Vreeker, R.: 2003, The Economics of Multiple Land Use, Shaker Publishing B.V., Maastricht.

Priemus, H., Nijkamp, P. and Dieleman, F. M.: 2000, Meervoudig Ruimtegebruik: Stimulansen en Belemmeringen, Delft University Press (in Dutch), Delft.

Roy, A. D.: 1951, Some thoughts on the distribution of earnings, Oxford Economic Papers 3, 135-146.

Sheehan, K.: 2001, E-mail survey response rates: A review, Journal of Computer Mediated Communication 6, [Online]-http://jcmc.indiana.edu/vol6/issue2/sheehan.html.

Song, Y. and Knaap, G.-J.: 2004, Measuring the effects of mixed land uses on housing values, Regional Science and Urban Economics 34, 663-680.

Van Wee, B.: 2003, Assessment of Benefits of Multifunctional Land Use, Shaker Publishing B.V., The Economics of Multifunctional Land Use, pp. 75-79.

Weisbrod, B.: 1964, Collective consumption services of individual consumption goods, Quarterly Journal of Economics 78, 471-477.

\section{A Correcting for Self-selection in the Choice of Facilities}

The observed WTPs in our dataset suffer from self-selection bias, because respondents first state their most preferred non-shopping facilities or most frequently visited shopping facilities and subsequently report their WTPs for the same facilities. Thus, observed WTP's are most likely positively biased if taken to represent the sample average, and do no reflect the mean WTP for each facility for the whole sample. In the early 1950's, Roy (1951) studied a similar problem 
where he described an elegant model dealing with the comparative productivity between hunters and fishermen in a very simple (autarchic) community. We will follow Roy's train of thought and apply it to our specific problem, first with only two facilities and next to a more general case.

Assume that there are two facilities at the Amsterdam Zuidas - e.g., a restaurant and a sport facility - from which an employee has to value her most important one. Employee $i$ will have a WTP of $X_{i}$ for a restaurant and a WTP of $Y_{i}$ for a sport facility. Employee $i$ will now be asked to express a WTP for a restaurant when $X_{i} \geq Y_{i}$ and a sport facility when $X_{i}<Y_{i}$. Now, assume that $(X, Y)$ is bivariate normally distributed, with expectation $\left(\mu_{X}, \mu_{Y}\right)$ and covariance matrix: ${ }^{11}$

$$
\left[\begin{array}{cc}
\sigma_{X}^{2} & \sigma_{X Y} \\
\sigma_{X Y} & \sigma_{Y}^{2}
\end{array}\right] .
$$

Thus, the WTPs for a restaurant and a sport facility are allowed to be correlated. For example, it may well be that workers who frequently visit restaurants have a higher preference for sport facilities as well. Or, those workers who like to sport may very well dislike visiting restaurants. Note that we are interested in the unconditional distributions of $X$ en $Y$; namely, the average value that all workers at the Amsterdam Zuidas would like to spend to make use of these facilities.

Now, define the residuals as follows (see for an elaboration Maddala 1983, pp. 257-258):

$$
u_{X}=X-\mu_{X}, u_{Y}=Y-\mu_{Y}
$$

Define the variance of the difference between the two residuals as follows:

$$
\sigma^{2}=\operatorname{Var}\left(u_{X}-u_{Y}\right)
$$

and finally define the standardized values:

$$
Z=\frac{\mu_{X}-\mu_{Y}}{\sigma}, u=\frac{u_{Y}-u_{X}}{\sigma},
$$

where $Z$ denotes the standardized difference in the WTPs between restaurants and sport facilities, and $u$ the standardized difference in deviations from the mean. Note that both $Z$ and $u$ are standard normally distributed. The condition $X>Y$ now implies $u<Z$, because, for those who indicated that they prefer a restaurant, the following expectation must yield:

\footnotetext{
${ }^{11}$ Roy's model critically depends on the normality assumption and has therefore been critized (see for further analysis Heckman and Honoré 1990).
} 


$$
E(X \mid X>Y)=E\left(X \mid \frac{\mu_{X}+u_{X}}{\sigma}>\frac{\mu_{Y}+u_{Y}}{\sigma}\right)=E(X \mid u<Z),
$$

which simplifies to (see also Maddala 1983, Greene 1993): ${ }^{12}$

$$
E(X \mid u<Z)=\mu_{X}-\sigma_{X u} \frac{\phi(Z)}{\Phi(Z)}
$$

with $\sigma_{X u}=\operatorname{Cov}\left(u_{X}, u\right)=\frac{\sigma_{X Y}-\sigma_{X}^{2}}{\sigma}$, and $\phi(\cdot)$ and $\Phi(\cdot)$ the density and cumulative distribution function respectively of the standard normal distribution. So, when there is a non-zero correlation between $u_{X}$ and the standardized difference between $u_{X}$ and $u_{Y}$, then the expectation is not only dependent upon the expectation of $u_{X}$, but also upon an additional term. This term, $-\frac{\phi(\cdot)}{\Phi(\cdot)}$, is also called the inverse Mills ratio, and basically depicts the probability that $Z$ is smaller or larger than $u .{ }^{13}$ Analogous to equation (A.1), the following expectation yields for those who indicated to prefer a sport facility:

$$
E(Y \mid X<Y)=E(Y \mid u>Z)=\mu_{Y}+\sigma_{Y u} \frac{\phi(Z)}{1-\Phi(Z)}
$$

with $\sigma_{Y u}=\operatorname{Cov}\left(u_{Y}, u\right)=\frac{\sigma_{Y}^{2}-\sigma_{X Y}}{\sigma}$. It is crucial to note that when $\sigma_{X u} \neq 0$ or $\sigma_{Y u} \neq 0$, linear regression on the observed WTP-values of both facilities using dummies for the choice for a particular type of facility yields biased results. Therefore, two-staged least squares or maximum likelihood methods have to be used.

Up to now we have only looked into a structure with two facilities. To generalise (A.1) and (A.2) to $N$ facilities, we use the following very useful property of the normal distribution; namely, assume that the WTPs of $N$ facilities are multivariate normally distributed, with $\mu$ the vector of expectations and $\boldsymbol{\Sigma}$ the covariance matrix, then for each subset, $y_{1}$, of $N$ must yield:

$$
y_{1} \sim N\left(\mu_{1}, \boldsymbol{\Sigma}_{11}\right)
$$

This means that each set of WTPs (and correspondingly, each single WTP) again has a normal distribution. Assume now that individuals first choose a facility $j$, which they subsequently value, then the following follows for the valuation $y_{j}$ of facility $j$ :

\footnotetext{
${ }^{12}$ Here we use the following property of the first moment of the truncated bivariate normal distribution (see also Greene 1993, p. 707):

$$
E(X \mid u<Z)=\frac{f(X)}{\operatorname{Pr}(u<Z)}=\mu_{X}+\sigma_{X u} \lambda\left(\alpha_{u}\right),
$$

with $\alpha_{u}=\frac{Z-E[u]}{\sqrt{\operatorname{Var}[u]}}=Z$ and $\lambda(\cdot)$ denoting the inverse Mills ratio $-\frac{\phi(\cdot)}{\Phi(\cdot)}$. The case for $u>Z$ can be derived completely analogously.

${ }^{13}$ Note that - unlike ordinary selection models - the standardized difference between the error terms is used here. This follows from the fact that both $X>Y$ and $X<Y$ may denote a selection process.
} 


$$
E\left(y_{j} \mid y_{j} \geq y_{k}, \forall k \neq j\right)=\mu_{j}-\sum_{k \neq j} \frac{\sigma_{j k}-\sigma_{j}^{2}}{\sigma} \frac{\phi(Z)}{\Phi(Z)},
$$

with $\sigma$ and $Z$ defined as above for each pair of facilities $z$ and $z^{\prime}$. For our purpose, however, individuals first choose $m$ (ordered) facilities, after which they will value them (separately for shopping facilities and aggregately for non-shopping facilities. Thus, if facilities $k$ are lower and facilities $l$ are higher valued than facility $j$, then the following must yield for facility $j$ :

$$
\begin{aligned}
E\left(y_{j} \mid y_{j} \geq y_{k} \wedge y_{j} \leq y_{l}, \forall k, l \neq j\right)=E\left(y_{j} \mid \xi_{j}\right)=\mu_{j} & -\sum_{k \neq j} \frac{\sigma_{j k}-\sigma_{j}^{2}}{\sigma} \frac{\phi(Z)}{\Phi(Z)} \\
& +\sum_{l \neq j} \frac{\sigma_{l}^{2}-\sigma_{j l}}{\sigma} \frac{\phi(Z)}{1-\Phi(Z)}
\end{aligned}
$$

where $\xi_{j}$ is a convenient shorthand notation for the ordering structure in the choices for the various facilities. Specification (A.4) now enables us to correctly estimate the WTP for both shopping and non-shopping facilities. 


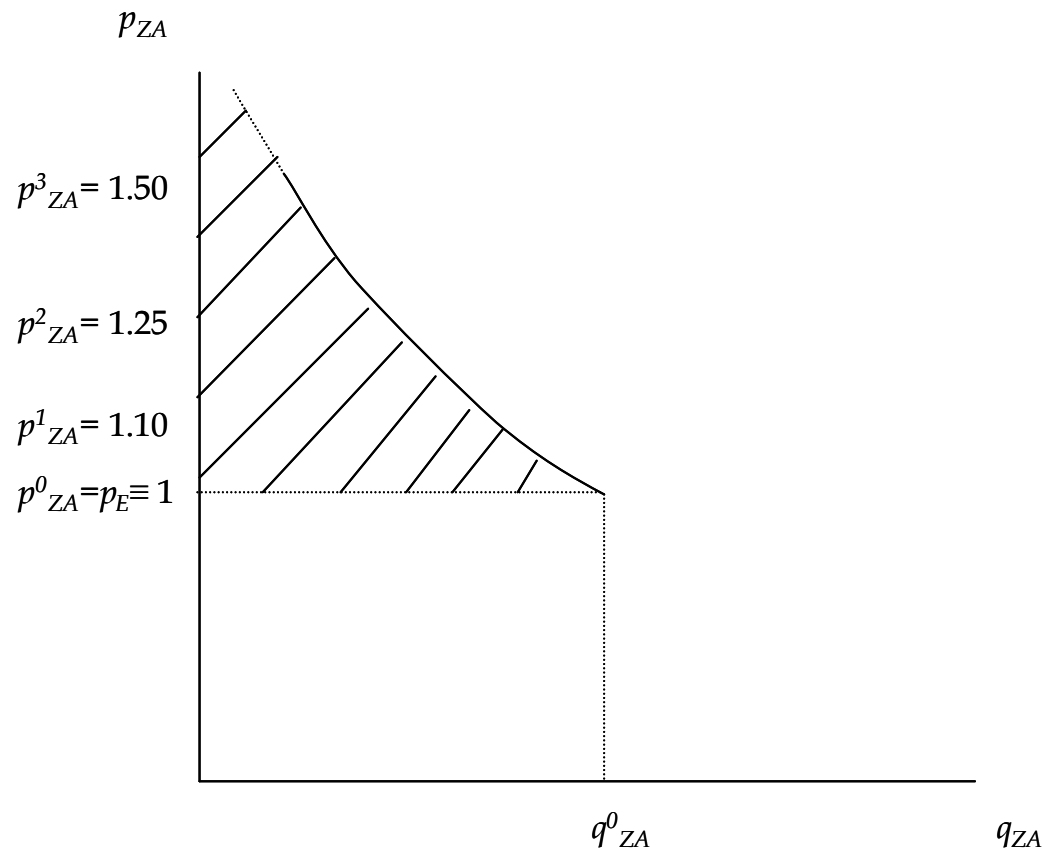

Figure 1: Relation between price level $\left(p_{Z A}\right)$ and expenditure level $\left(q_{Z A}\right)$ at the Amsterdam Zuidas (ZA) 


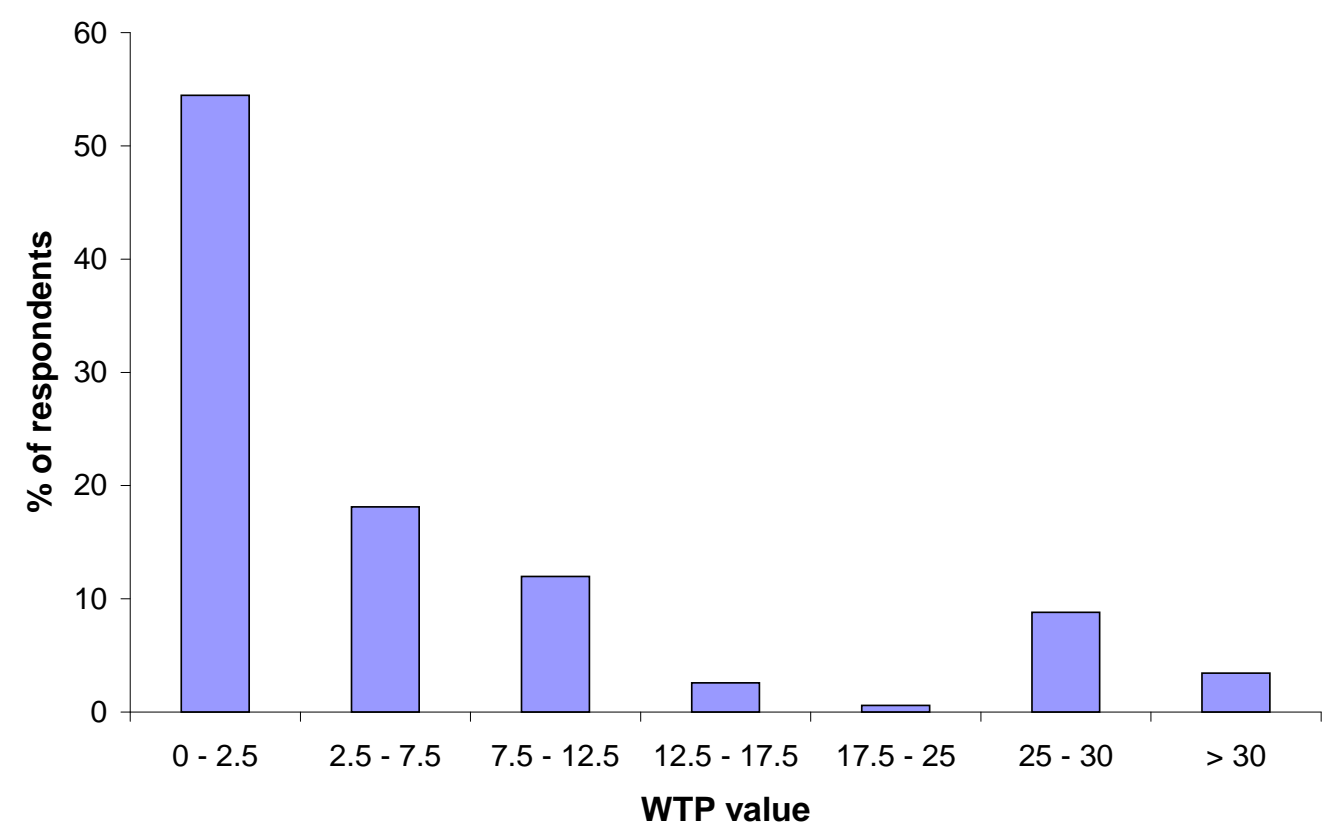

Figure 2: Frequencies of WTP values for sets of three most-preferred non-shopping facilities 


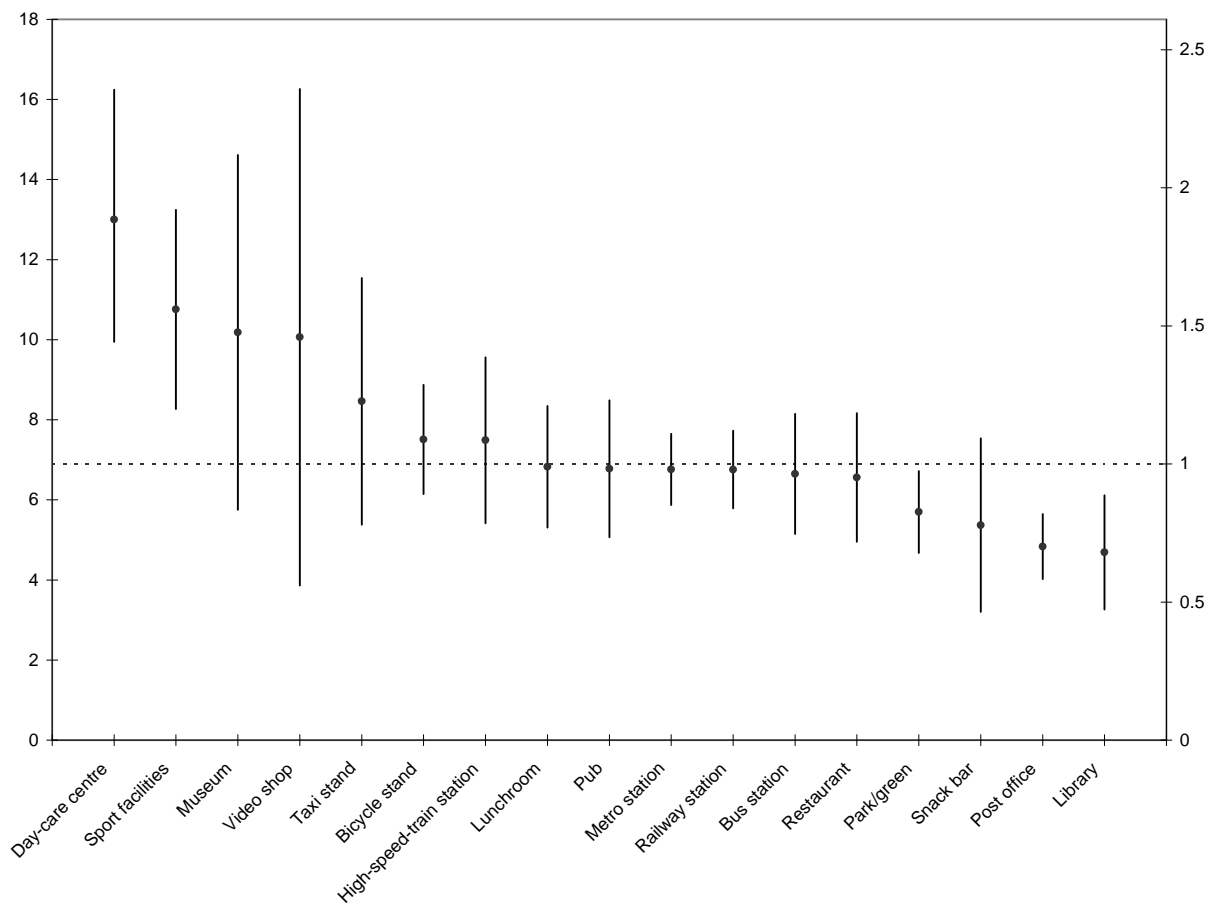

Figure 3: Average WTP values for bundles in which indicated facility is included (WTP on left axis, WTP divided by average WTP on right axis) 


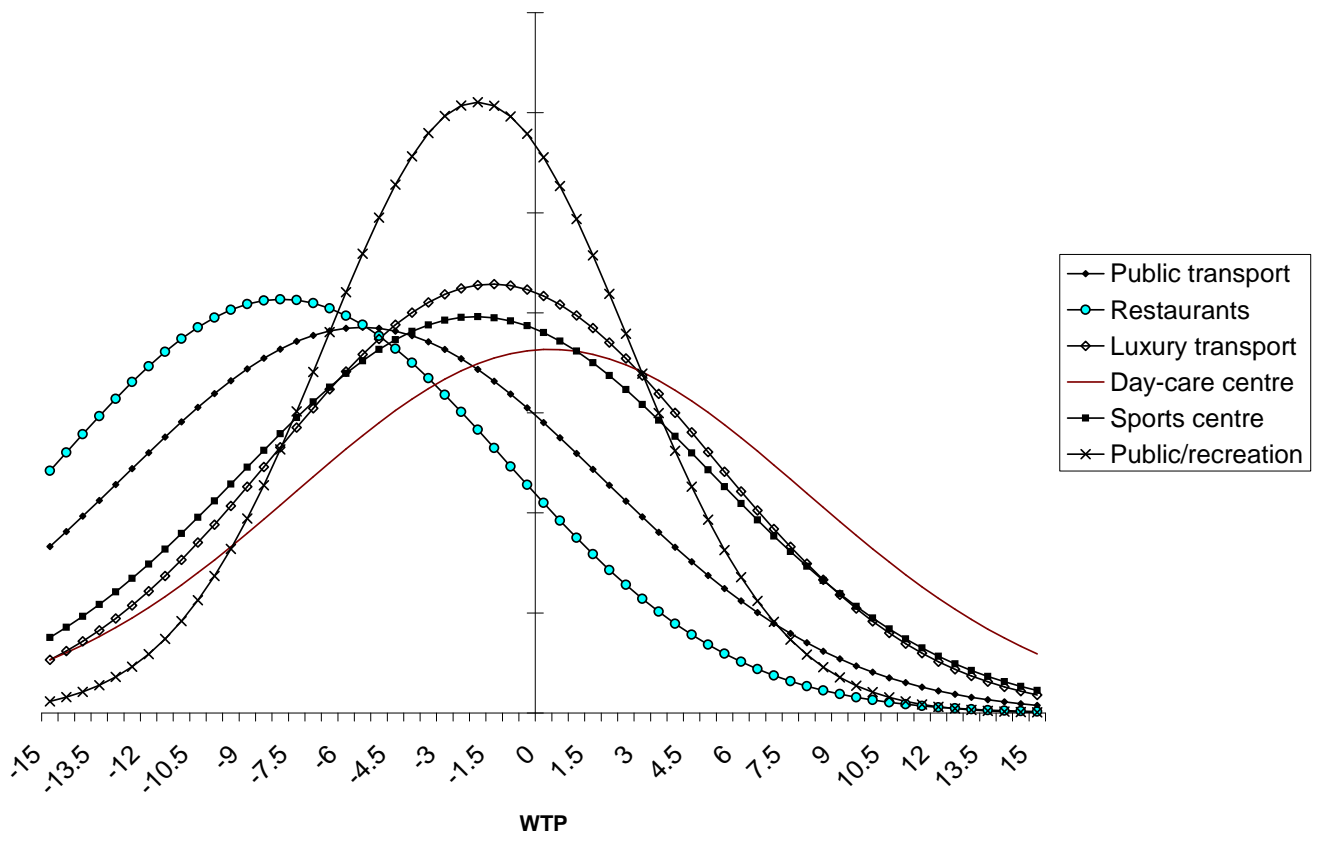

Figure 4: Estimated normal density functions of latent WTP values for non-shopping facilities at the Amsterdam Zuidas 
Table 1: Characteristics of the Respondents (percentages of population)

\begin{tabular}{|c|c|c|}
\hline Characteristics & Value Zuidas & Value Netherlands \\
\hline \multicolumn{3}{|l|}{ Gender } \\
\hline Male & 59 & 59 \\
\hline \multicolumn{3}{|l|}{ Age } \\
\hline$<30$ & 26 & 23 \\
\hline $31-40$ & 35 & 29 \\
\hline$>41$ & 39 & 48 \\
\hline \multicolumn{3}{|l|}{ Highest Educational Degree } \\
\hline Bachelor/Master & 82 & 27 \\
\hline High School & 16 & 64 \\
\hline Other & 2 & 8 \\
\hline \multicolumn{3}{|l|}{ Working Days per Week } \\
\hline 3 or less & 10 & 17 \\
\hline 4 & 31 & 20 \\
\hline 5 & 59 & 63 \\
\hline \multicolumn{3}{|l|}{ Main Mode of Commuting } \\
\hline Car & 29 & 60 \\
\hline Public Transport & 38 & 8 \\
\hline Bicycle & 30 & 25 \\
\hline Other Transport Modes & 3 & 7 \\
\hline \multicolumn{3}{|l|}{ Net Personal Monthly Income } \\
\hline$<€ 2000$ & 35 & 90 \\
\hline$€ 2000-€ 3000$ & 30 & 3 \\
\hline$>€ 3000$ & 27 & 1 \\
\hline Unknown & 5 & 6 \\
\hline \multicolumn{3}{|l|}{ Family Situation } \\
\hline Living Alone without Children & 26 & 14 \\
\hline Living Alone with Children & 2 & 3 \\
\hline Living with Partner and with Children & 38 & 54 \\
\hline Living with Partner and without Children & 34 & 29 \\
\hline \multicolumn{3}{|l|}{ Partner (when living together) } \\
\hline Works Fulltime & 51 & 14 \\
\hline
\end{tabular}


continued from previous page

\begin{tabular}{|c|c|c|}
\hline Characteristics & Value Zuidas & Value Netherlands \\
\hline \multicolumn{3}{|l|}{ Work Location } \\
\hline$<2$ min. walking from WTC Railway Station & 50 & \\
\hline
\end{tabular}


Table 2: Estimation results for non-shopping facilities (at 5\% significant in bold)

\begin{tabular}{|c|c|c|}
\hline Variabele & Coefficient & Standard error \\
\hline \multicolumn{3}{|l|}{ Age (base $\leq 30)$} \\
\hline $31-40$ & 1.73 & 1.97 \\
\hline$>41$ & 0.42 & 2.40 \\
\hline missing & -2.55 & 1.73 \\
\hline \multicolumn{3}{|l|}{ Travel days (base $=1-3$ ) } \\
\hline 4 & 7.32 & 0.29 \\
\hline 5 & 6.66 & 0.45 \\
\hline \multicolumn{3}{|l|}{ Income (base $\leq € 1500$ ) } \\
\hline Unknown $(5.1 \%)$ & 5.46 & 1.26 \\
\hline$€ 1500-2000$ & 0.02 & 3.56 \\
\hline$€ 2000-3000$ & 0.53 & 1.70 \\
\hline$>€ € 3000$ & 0.00 & 15.48 \\
\hline \multicolumn{3}{|c|}{ Travel time (base $=0-10$ minutes) } \\
\hline $10-20$ minutes & 1.47 & 0.84 \\
\hline $20-30$ minutes & 1.43 & 0.93 \\
\hline $30-45$ minutes & 5.69 & 0.80 \\
\hline $45-60$ minutes & 3.83 & 1.17 \\
\hline$>60$ Minutes & -2.04 & 0.56 \\
\hline \multicolumn{3}{|l|}{ Transport mode $($ base $=$ car $)$} \\
\hline Train & 3.39 & 1.35 \\
\hline Tram/bus & 3.42 & 1.43 \\
\hline Walk/bike & -1.01 & 2.03 \\
\hline Other transport means & -0.45 & 0.93 \\
\hline \multicolumn{3}{|l|}{ Gender $($ base $=$ male $)$} \\
\hline female & 4.05 & 2.15 \\
\hline \multicolumn{3}{|c|}{ Urbanization at place of residence (base $=<500$ addresses per $\mathrm{km} 2$ ) } \\
\hline $500<1000$ & 5.90 & 1.25 \\
\hline $1000<1500$ & -0.78 & 1.02 \\
\hline $1500<2500$ & -0.05 & 2.42 \\
\hline$\geq 2500$ & -0.27 & 8.52 \\
\hline missing & 4.04 & 0.75 \\
\hline
\end{tabular}


continued from previous page

\begin{tabular}{lrr}
\hline \hline Variabele & Coefficient & Standard error \\
\hline Distribution parameters & & \\
$\mu_{\text {public transport }}$ & $\mathbf{- 5 . 5 1}$ & 1.10 \\
$\mu_{\text {restaurants }}$ & $\mathbf{- 7 . 9 4}$ & 1.59 \\
$\mu_{\text {luxury transport }}$ & $\mathbf{- 1 . 5 6}$ & 1.49 \\
$\mu_{\text {day-care centre }}$ & 0.21 & 1.91 \\
$\mu_{\text {sports centre }}$ & -2.04 & 1.89 \\
$\mu_{\text {Public/recreation }}$ & $\mathbf{- 2 . 0 1}$ & 0.86 \\
$\sigma_{\text {public transport }}$ & 7.32 & 14 \\
$\sigma_{\text {restaurants }}$ & 6.82 & - \\
$\sigma_{\text {luxury transport }}$ & 6.58 & - \\
$\sigma_{\text {day-care centre }}$ & 7.76 & - \\
$\sigma_{\text {sports centre }}$ & 7.12 & - \\
$\sigma_{\text {Public/recreation }}$ & 4.62 & 1518 \\
\hline Number of observations & & 0.49 \\
\hline Mean loglikelihood & & \\
\hline \hline
\end{tabular}

\footnotetext{
${ }^{14}$ Due to a reparametrization of the (co)variance parameters using a Choleski decomposition, standard errors of the $\sigma$ 's can not be provided (Greene 1993).
} 
Table 3: Expected WTP for non-shopping facilities

\begin{tabular}{lr}
\hline \hline Facility & Expected WTP \\
\hline Public transport & $€ 2.56$ \\
Restaurants & $€ 2.15$ \\
Luxury transport & $€ 1.59$ \\
Day-care centre & $€ 2.46$ \\
Sports centre & $€ 1.96$ \\
Public/recreation & $€ 0.59$ \\
\hline Total WTP & $€ 29.39$ \\
\hline \hline
\end{tabular}


Table 4: Estimation results for shopping facilities (at 5\% significant in bold)

\begin{tabular}{lrr}
\hline \hline Variabele & Coefficient & Standard error \\
\hline Age (base $\leq 30)$ & & \\
$31-40$ & $\mathbf{- 0 . 0 4 1}$ & 0.005 \\
$>41$ & $\mathbf{- 0 . 0 7 6}$ & 0.006 \\
missing & $\mathbf{- 0 . 0 6 3}$ & 0.011 \\
Travel days (base $=1-3)$ & & \\
4 & $\mathbf{0 . 0 2 3}$ & 0.006 \\
5 & $\mathbf{0 . 0 2 3}$ & 0.006 \\
Income (base $\leq € 1500)$ & & 0.009 \\
Unknown $(5.1 \%)$ & $\mathbf{0 . 0 3 6}$ & 0.006 \\
$€ 1500-2000$ & 0.011 & 0.006 \\
$€ 2000-3000$ & $\mathbf{0 . 0 2 2}$ & 0.007 \\
$>€ 3000$ & 0.009 &
\end{tabular}

Travel time (base $=0-10$ minutes)

$\begin{array}{lll}10-20 \text { minutes } & \mathbf{- 0 . 0 4 6} & 0.007 \\ 20-30 \text { minutes } & \mathbf{- 0 . 0 7 5} & 0.007 \\ 30-45 \text { minutes } & \mathbf{- 0 . 0 9 1} & 0.007 \\ 45-60 \text { minutes } & \mathbf{- 0 . 1 1 0} & 0.008 \\ >60 \text { Minutes } & \mathbf{- 0 . 1 1 0} & 0.009\end{array}$

Transport mode $($ base $=$ car $)$

$\begin{array}{lrr}\text { Train } & \mathbf{- 0 . 0 1 6} & 0.006 \\ \text { Tram/bus } & \mathbf{0 . 0 3 9} & 0.006 \\ \text { Walk/bike } & \mathbf{- 0 . 0 4 2} & 0.006 \\ \text { Other transport means } & \mathbf{- 0 . 0 2 3} & 0.011\end{array}$

Gender (base $=$ male $)$

$\begin{array}{lll}\text { female } & \mathbf{0 . 0 2 7} & 0.004\end{array}$

Urbanization at place of residence (base $=<500$ addresses per $\mathrm{km} 2$ )

\begin{tabular}{lrl}
$500<1000$ & $\mathbf{- 0 . 0 2 1}$ & 0.005 \\
$1000<1500$ & $\mathbf{- 0 . 0 1 5}$ & 0.007 \\
$1500<2500$ & $\mathbf{- 0 . 0 2 8}$ & 0.008 \\
$\geq 2500$ & $\mathbf{0 . 0 3 3}$ & 0.010 \\
missing & $\mathbf{- 0 . 0 3 4}$ & 0.007 \\
\hline
\end{tabular}

continued on next page 
continued from previous page

\begin{tabular}{|c|c|c|}
\hline Variabele & Coefficient & Standard error \\
\hline \multicolumn{3}{|c|}{ Price dummies for supermarket } \\
\hline$p_{Z A}=1.0$ & 0.374 & 0.011 \\
\hline$p_{Z A}=1.1$ & 0.256 & 0.011 \\
\hline$p_{Z A}=1.25$ & 0.168 & 0.010 \\
\hline$p_{Z A}=1.5$ & 0.120 & 0.010 \\
\hline
\end{tabular}

Price dummies for drugstore

$\begin{array}{lll}p_{Z A}=1.0 & \mathbf{0 . 4 8 6} & 0.013 \\ p_{Z A}=1.1 & \mathbf{0 . 3 3 0} & 0.013 \\ p_{Z A}=1.25 & \mathbf{0 . 1 8 7} & 0.011 \\ p_{Z A}=1.5 & \mathbf{0 . 1 0 8} & 0.012\end{array}$

Price dummies for dry cleaners

$\begin{array}{lrl}p_{Z A}=1.0 & \mathbf{0 . 5 5 8} & 0.022 \\ p_{Z A}=1.1 & \mathbf{0 . 3 4 2} & 0.023 \\ p_{Z A}=1.25 & \mathbf{0 . 0 6 6} & 0.022 \\ p_{Z A}=1.5 & \mathbf{- 0 . 0 7 5} & 0.019\end{array}$

Price dummies for bookshop

$\begin{array}{lll}p_{Z A}=1.0 & \mathbf{0 . 5 0 0} & 0.015 \\ p_{Z A}=1.1 & \mathbf{0 . 3 0 6} & 0.016 \\ p_{Z A}=1.25 & \mathbf{0 . 1 3 9} & 0.014 \\ p_{Z A}=1.5 & \mathbf{0 . 0 6 1} & 0.013\end{array}$

Price dummies for flower shop

$\begin{array}{lll}p_{Z A}=1.0 & \mathbf{0 . 4 6 9} & 0.015 \\ p_{Z A}=1.1 & \mathbf{0 . 3 3 5} & 0.015 \\ p_{Z A}=1.25 & \mathbf{0 . 1 6 7} & 0.014 \\ p_{Z A}=1.5 & \mathbf{0 . 0 7 1} & 0.014\end{array}$

Price dummies for hairdresser

\begin{tabular}{|c|c|c|}
\hline$p_{Z A}=1.0$ & 0.364 & 0.046 \\
\hline$p_{Z A}=1.1$ & 0.210 & 0.044 \\
\hline$p_{Z A}=1.25$ & -0.104 & 0.052 \\
\hline$p_{Z A}=1.5$ & -0.233 & 0.035 \\
\hline
\end{tabular}

continued on next page 
continued from previous page

\begin{tabular}{lrr}
\hline Variabele & Coefficient & Standard error \\
\hline Mean loglikelihood & & 0.23 \\
\hline \hline
\end{tabular}


Table 5: Expenditure share and expected WTP values for shopping facilities at the Zuidas

\begin{tabular}{lrr}
\hline \hline Facility & Expenditure share & Expected WTP \\
\hline Supermarket & $4.76 \%$ & $€ 12.37$ \\
Drugstore & $5.08 \%$ & $€ 1.77$ \\
Dry cleaners & $3.65 \%$ & $€ 0.05$ \\
Bookshop & $3.43 \%$ & $€ 0.91$ \\
Flower shop & $4.24 \%$ & $€ 0.48$ \\
Hairdresser & $1.57 \%$ & $€ 0.20$ \\
\hline Total WTP & & $€ 15.79$ \\
\hline \hline
\end{tabular}

